\title{
Corpus
}

\section{¿Sueñan las estatuas con ovejas de bronce?}

\section{Paolo Vignolo}

\section{(2) OpenEdition}

Journals

Electronic version

URL: https://journals.openedition.org/corpusarchivos/4520

ISSN: 1853-8037

\section{Publisher}

Diego Escolar

Electronic reference

Paolo Vignolo, «¿Sueñan las estatuas con ovejas de bronce?», Corpus [En línea], Vol. 11, №. 1 | 2021,

Publicado el 28 junio 2021, consultado el 03 julio 2021. URL: http://journals.openedition.org/

corpusarchivos/4520

This text was automatically generated on 3 July 2021.

Licencia Creative Commons: Atribución-NoComercial 2.5 Argentina (CC BY-NC 2.5 AR) 


\title{
¿Sueñan las estatuas con ovejas de bronce?
}

\author{
Paolo Vignolo
}

1 De entrada, quisiera aclarar algo: nunca me han caído bien las estatuas conmemorativas. Por lo general las miro con un mixto de desdén y fastidio, en el mejor de los casos las ignoro. Sea quien sea el personaje en cuestión, a mis ojos representan todo lo que menos me agrada de una historia varonil, grandilocuente, a menudo militarista.

2 Monolitos de miradas heroicas que desconocen el parpadeo y el sueño, cumplen con la función de reificar el pasado en una promesa de eternidad que no es de este mundo. Son la negación misma de la memoria, esa extraordinaria facultad humana de movilizar a la vez los recuerdos y la imaginación. Representan un patrimonio atrapado en su propia etimología de Pater-Patria-Patrón, si de categorías de género, nación y clase queremos hablar. Y Pater Noster también, para no olvidarnos de los procesos de evangelización y colonización.

3 No me caían nada bien esos colosos de oficialidad, hasta que de repente... (¿Quién se lo hubiera imaginado en ese comienzo de milenio?) una oleada de revueltas populares las derriba de sus pedestales. Conquistadores sanguinarios, traficantes de seres humanos y generales genocidas, consagrados a la gloria inmarcesible de Estados que a menudo menosprecian a su propia gente, están ahora expuestos al escarnio público. Pintadas, escraches, martillazos, ahorcamientos... retumbos de revolución en la iconosfera, ponen a temblar el ancién regime de una memoria institucional que ofende a las víctimas de ayer y de hoy.

4 Gestos colectivos potentes. Gestos emancipadores, y no solo para quienes - y somos muchos -vemos en ese corpus monumental una obscena exhibición de un cuerpo de la nación excluyente y opresivo. Gestos emancipadores también para las mismas estatuas.

El destello insurreccional sacude el objeto-estatua del sujeto que tiene que representar. En su cruda materialidad, en cuanto significante liberado del yugo de personaje que la significaba, el monumento se vuelve signo abierto, renace a nueva vida. Una nuda vida, si Agamben (2010[1995]) me da licencia. Algo parecido a lo que les pasa a los replicantes 
Nexus-6 de Blade Runner, implacables androides de guerra, al despertarse de su primer sueño poblado de ovejas eléctricas. ${ }^{1} \mathrm{Y}$ acá me sorprendo a mirar las estatuas con cierta ternura. Ya me resultan más simpáticas, lo confieso. Creaturas trágicas y antiguas, Golems que han cargado con los horrores del pasado y ahora dan sus primeros sollozos por el mundo. ¿Qué vamos a hacer con estas estatuas caídas en desgracia?

Repararlas, limpiarlas y volverlas a poner en su lugar sería un acto de restauración, la negación misma de las movilizaciones sociales y de sus razones. Como pasó en Bogotá, donde el alcalde, impávido frente al ridículo, decidió no solo hacer repulir la escultura de Cristóbal Colón -a menudo objeto de grafitis contestatarios- sino, además, voltearla 22.5 grados hacia occidente, para que la mano de Colón indique la "verdadera" ruta hacia las Indias.

7 Pero tampoco creo que haya que inferir contra ellas. Si la decapitación del tirano puede ser gesto revolucionario, la tortura ya es pura crueldad. Además, la iconoclastia hecha sistema inconscientemente termina admitiendo su temor reverencial frente a los mismos poderes de lo sagrado que quiere derribar. Ahora que la dialéctica amo-esclavo en versión artífice-artefacto se ha puesto en marcha, ya me daría pesar verlas hechos pedazos, en alguna bodega de museo, en algún basurero de la historia.

8 No quiero que me malentiendan: soy sensible a la estética del fragmento, a la poética del escombro, pero la aprecio más cuando está al servicio de la reparación simbólica, no de la venganza. Me conmuevo cada vez que veo el Cristo Negro mutilado entre las ruinas de la Iglesia de Bojayá, donde más de 80 personas fueron asesinadas en 2002 por la explosión de una pipeta de gas lanzada por el frente 58 de las FARC, en un enfrentamiento con el Bloque paramilitar Elmer Cárdenas (Bojayá: la guerra sin límites, 2010).

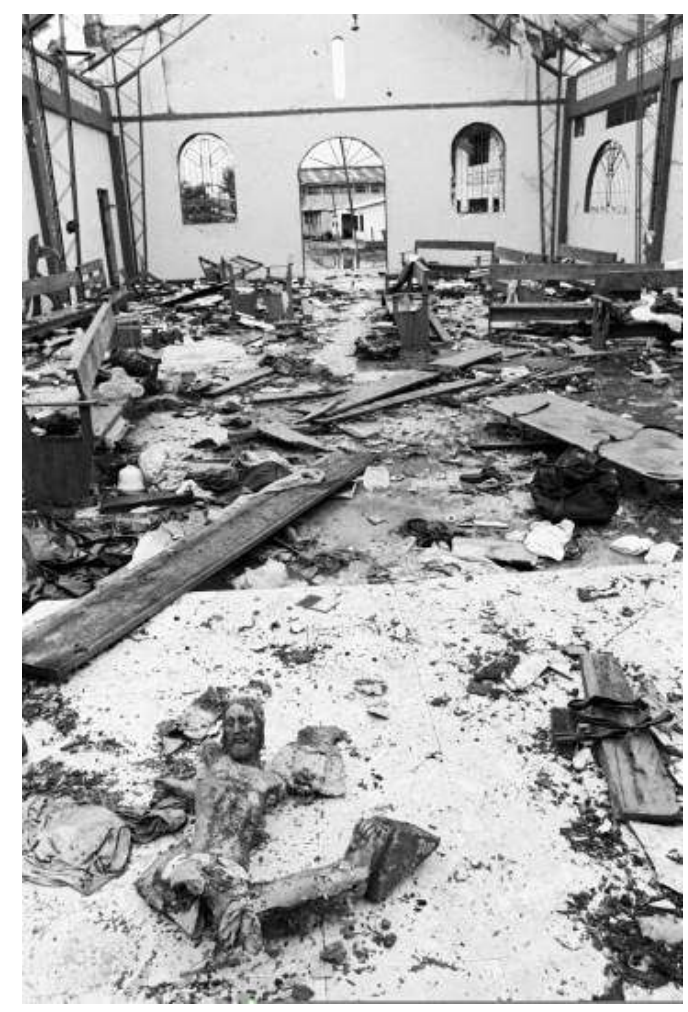

Imagen $N^{\circ} 1$. El Cristo de Bojayá. Foto: Jesús Abad Colorado, 2002 
"El Cristo de Bojayá de alguna forma es nuestro Guernica", dijo el fotógrafo Jesús Abad Colorado, autor de las más sobrecogedoras fotos de la guerra colombiana al recibir un premio en 2019 (El País, 4-10-2019). Estoy de acuerdo. Bien hicieron los habitantes de Bojayá en conservar esa figura de cuerpo dos veces martirizado como reliquia y monumento a las víctimas, frente a la cual han tenido que postrarse comandantes guerrilleros, jefes paramilitares, autoridades del Estado, hasta el mismo Papa. Si las estatuas se han desprendido, aunque por pocas horas, de las jaulas epistémicas y de las cadenas interpretativas que las ataban a una lectura oficial de lo que pasó, pueden volverse protagonistas de lo que está pasando y podría pasar. Monumentos insurrectos, ya son potenciales aliados de nuestras causas.

10 En la mayoría de los casos siguen siendo bastantes feas, es cierto. Están hecha a imagen y semejanza de mercaderes sin escrúpulos, políticos corruptos, reyes y militares con las manos manchadas de sangre. Empero, ¿Cuántos descendientes de personas esclavizadas llevan el nombre, cuando no los genes, de sus esclavizadores? ¿Cuánto de nosotros humanos fuimos hechos (así nos cuentan) a imagen y semejanza de dioses que ahora desconocemos? Nadie puede ser tachado de las culpas de quien los trajo al mundo. Hasta la estatua más espantosa tiene el derecho a una segunda inauguración: destaparse de sus viejos trajes para relucir otro semblante, poiesis de lo político en lo poético.

11 Estoy seguro que la escultura de Isabel la Católica en La Paz (Bolivia) se ha sentido mucho más cómoda en su plaza de La Paz desde que las activistas del Colectivo Mujeres Creando la arroparon con una pollera, una manta amarilla, un atado de aguayo y un sombrero. Vestida como una chola del altiplano, se relaciona mejor con los habitantes de la capital boliviana (Pau, 2020). A veces es suficiente una peluca afro, como la que desde 2008 Nelson Fory le va poniendo en Cartagena, Cali y Bogotá a próceres y conquistadores. Con esta pinta carnavalesca las estatuas de Pedro de Heredía, Cristobal Colón y del mismo Simón Bolivar ya parecen tirar pasos de salsa al ritmo de Joe Arroyo (Alberty Garcés, 2015). Y el Simón Bolívar del centro de la capital colombiana ha logrado conectarse con la ciudadanía como quizás no pasaba de los tiempos de sus gestas libertadoras, desde que se ha vuelto costumbre ponerle camisetas y gorros de cuanta marcha de protesta y movilización se tenga en la plaza que lleva su nombre.

12 De todas maneras, no quiero llevar demasiado lejos esa inesperada pietas por las estatuas, que hasta ahora me atrevo a expresar públicamente. Está bien permitir que esos vestigios de memoria patriotera, una vez bajadas de sus pedestales, pueden tener su vida social, como cualquier otro objeto. Pero no creo sea buena idea seguir produciendo más de esos androides replicantes.

13 Por eso me niego a pensar que el camino a seguir sea sustituir las estatuas de los malos con las estatuas de los buenos, el conquistador con la mujer indígena, el vencedor celebrado ayer con el vencido recién rescatado. $O$ de poner a convivir los uno con los otros, en una apoteosis monumental de lo políticamente correcto. La propuesta de la Academia Colombiana de Historia de ubicar "la representación de un indígena guambiano en actitud desafiante" al frente de la estatua ecuestre de Sebastián de Belalcázar derribada por ungrupo de indígenas misak me parece una triste mimesis de la estética de los dominadores (Pérez Benavides y Vargas Alvarez, 2021). 


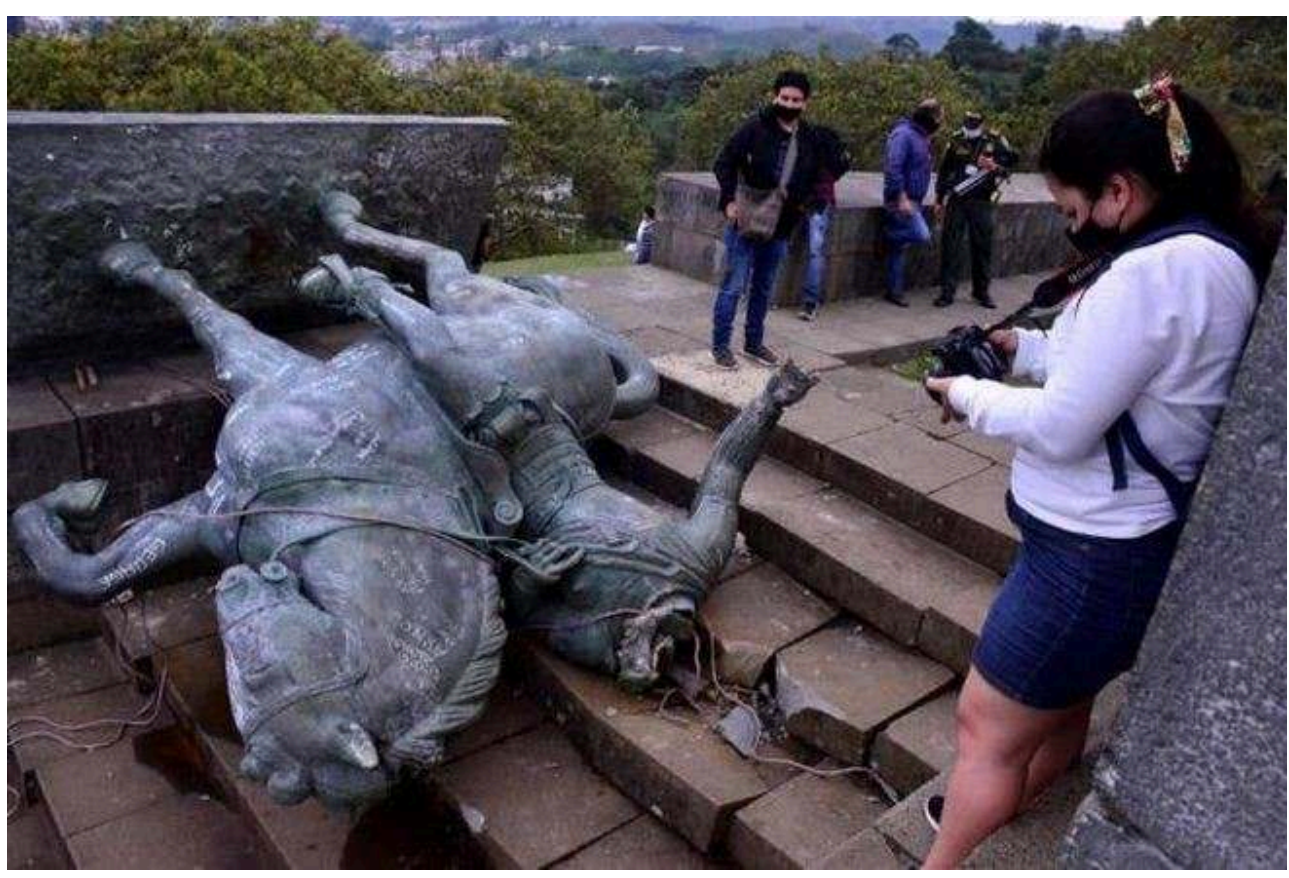

Imagen $N^{\circ}$ 2. Indígenas misak derribaron estatua de Belalcazar en Cali. Foto: Agencia Efe

14 Si de plasmar la memoria colectiva a imagen y semejanza de lo humano se trata, otros son los dispositivos que propondría de acá en adelante: performances, murales, instalaciones, contra-monumentos...Como la carroza "El Colorado," por ejemplo, que en 2018 triunfó en el carnaval de Pasto al poner en escena la masacre de la Navidad Negra de 1822, cuando las tropas del general Antonio José de Sucre, atendiendo órdenes expresas de Simón Bolívar, sometieron la ciudad a sangre y fuego.

O las protografías de Oscar Muñoz: rostros efímeros que se pierden en el remolino del tubo de desagüe de un lavamanos, retratos que se desvanecen a pesar de los esfuerzos de una mano que los sigue dibujando, caras que solo aparecen con el aliento de quien las mira (Sánchez Gómez, 2011; Escallón, 2014). Imágenes frágiles, volubles, que se sepan mirarse a sí mismas en el espejo de los demás. Como nosotros los humanos, como nuestras memorias.

Déjeme terminar con una historia poco conocida, que aprendí del trabajo de investigación que Marcela Fernanda Pardo García llevó a cabo bajo mi tutoría (Pardo García 2020). Es la historia de la Muñeca de Libertad, un pequeño corregimiento a dos horas de Cartagena, en la costa caribe colombiana. El 1 de julio de 1998 una copia de la Estatua de la Libertad de tres metros en fibra de vidrio, con una lámpara en vidrio tallado en sustitución de la antorcha, es decomisada por funcionarios del aeropuerto de Bogotá. Con toda probabilidad se trata de un capricho de algún narcotraficante que la querría exhibir en su propia mansión: pequeños contrabandos a la frontera del sueño americano, nada más.

Luego de tres años de cautiverio en los sótanos de la División de Impuestos y Aduanas Nacionales -DIAN, el Estado hace oficial donación del estrafalario objeto a la Fundación Progresar, una organización de ex combatientes de la guerrilla desmovilizada del Ejercito Liberación Popular. Junto con la estatua, en cumplimiento con el Plan de Reinserción, también se entregan a la Fundación cajas de secadores de pelo, labiales, lápices para los ojos, partes de mobiliario... 
18 Nadie sabe qué hacer con este artefacto, demasiado voluminoso para la pequeña sede, demasiado simbólico para botarlo a la basura. La estatua pasa un tiempo en el jardín de la casa de Vera Grabe, ex guerrillera del M-19, luego más de diez años guardada en una bodega. Hasta se intenta venderla en Mercado Libre, pero nadie ofrece nada por su rescate. Finalmente, la estatua llega en manos del artista plástico Camilo Conde, que decide regalársela a un grupo de mujeres negras que se están organizando para denunciar la práctica sistemática de violencia sexual en la costa por parte del grupo paramilitar al mando de "Alias El Oso".

19 El 12 de junio de 2014, luego de una travesía por medio país, amarrada en el techo de un Rand Rover modelo '79, la réplica de la Estatua de la Libertad hace su entrada al corregimiento de Libertad, municipio de San Onofre, recibida con un mixto de asombro y entusiasmo por Nergina Gúzman, Isabel Martínez, Modesta Sarmiento, Adriana Porras y las demás mujeres de la asociación. Deciden instalarla en el parque central del pueblo. Desde ese momento la Estatua de la Libertad se vuelve su muñeca, su santa y su marucha: el icono de Estados Unidos se transforma en la protectora de las luchas feministas en medio de la guerra en Colombia.

20 Sin embargo, en un primer momento la irrupción de la estatua en el pueblo se enfrenta a polémicas y sospechas. La gente se está preparando a conmemorar por primera vez el Día de la Resistencia, para recordar que diez años antes un grupo de vecinos se había sacudido del yugo paramilitar, matando a palos y piedras a "Alias Diomedes", uno de sus comandantes más feroces. Con el incipiente proceso de paz, ya se puede hacer memoria de aquel momento de rescate de la dignidad popular. Pero, ¿Qué tiene que ver aquella estatua intrusa?

21 Hasta ese momento el trabajo de memoria histórica no había incluido la cuestión de la violencia sexual, jamás confesada ni por "Alias el Oso" ni para los demás paramilitares. Era una historia vergonzosa por las familias, hechas de silencios e insinuaciones. Solo gracias a los debates, los cuentos, los cantos de Marruchas y los bailes al ritmo de bullerengue que acompañan la pintada y la instalación de la Muñeca de Libertad en el parque central, la comunidad llega a reconocer la victimización de las mujeres del pueblo y su valentía en contar sus vivencias como parte de la resistencia al conflicto armado. 


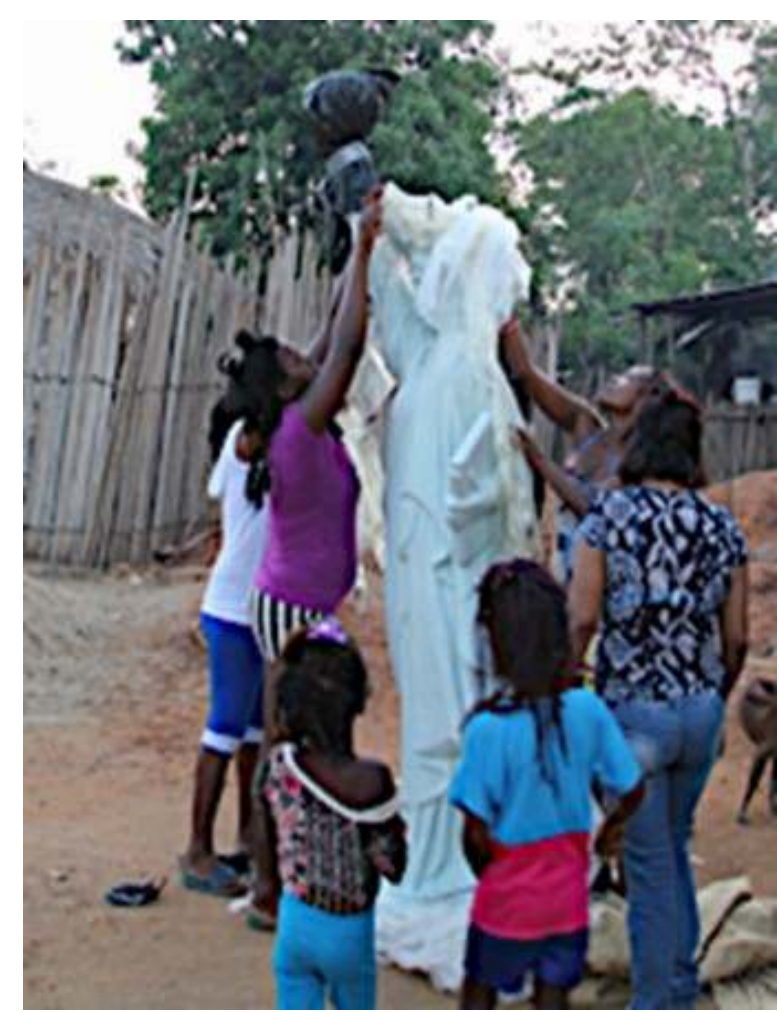

Imagen N³: Taller de la muñeca de Libertad. Foto: Marcela Fernanda Pardo García

22 A través de un trabajo colectivo de niños, jóvenes y mujeres liderado por Camilo, se va despojando de sus trajes neoclásicos y su postura imperialista, para tomar las semblanzas de una negra cimarrona de traje blanco, con adornos florales de colores alegres. Hoy en día la Muñeca de Libertad es el mayor atractivo del pueblo. A todo visitante se le cuenta la historia de las mujeres liberteñas que supieron denunciar los horrores de la guerra y reconquistar la identidad propia y de toda una comunidad. 


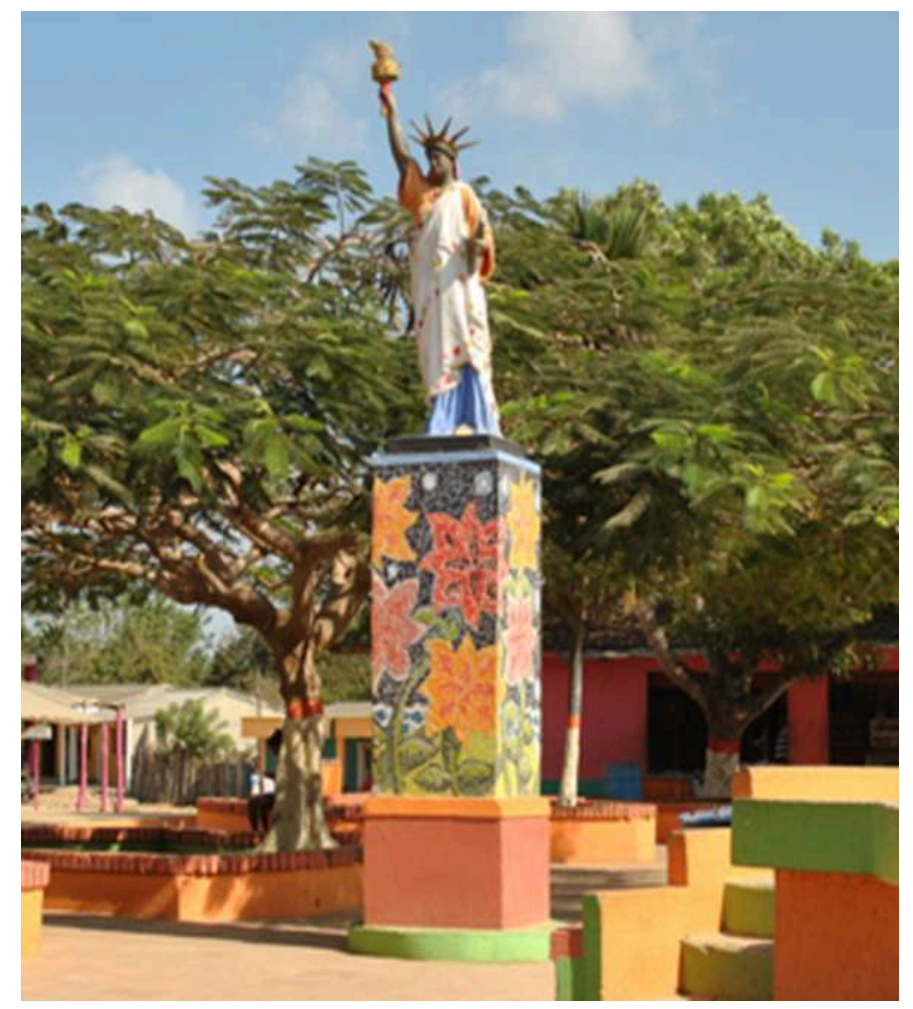

Imagen N4: Muñeca de Libertad. Fuente: Marcela Fernanda Pardo García

\section{BIBLIOGRAPHY}

Alberty Garcés, D. (2015) “¡La historia nuestra, Caballero! Turismo, invisibilidad y gentrificación”. Cuadernos de Música, Artes Visuales y Artes Escénicas, 10(2), 57-70, 2015. https:// revistas.javeriana.edu.co/index.php/cma/article/view/13745 Consultado el 10/06/2021

Agamben, G. (2010[1995]). Homo sacer. Il potere sovrano e la nuda vita Torino: Einaudi.

¡Basta Ya! Colombia: Memorias de guerra y dignidad Informe General Grupo de Memoria Histórica. Bogotá: Centro Nacional de Memoria Histórica, 2013, p.88 https://

www.centrodememoriahistorica.gov.co/descargas/informes2013/bastaYa/basta-ya-colombiamemorias-de-guerra-y-dignidad-2016.pdf Consultado el 10/06/2021

Bojayá: la guerra sin límites.(2010) Bogotá: Grupo memoria histórica; Ediciones Semana.

Dick, P. (1982). ¿Sueñan los androides con ovejas eléctricas? Barcelona: Edhasa.

Escallón, A. M.(2014) «La memoria y el olvido en Oscar Muñoz». Las 2 orillas, 18/01/2014 https:// www.las2orillas.co/la-memoria-el-olvido-en-oscar-munoz/ Consultado el 10/06/2021

Oquendo C. y Torrado, S. (2019) Entrevista a Jesús Abas Colorado. El País, 4/10/2019.https:// elpais.com/cultura/2019/10/04/actualidad/1570203851_185291.html Consultado el 10/06/2021 
Pardo García, M. F.(2020). La muñeca de Libertad. Ejercicios de contramemoria de las mujeres del corregimiento de Libertad, en San Onofre, Sucre. Tesis de maestría en estudios culturales, Bogotá : Universidad Nacional de Colombia.

Pau, Alejandra (2020). "Mujeres Creando pinta y viste de chola la escultura de Isabel la Católica", Pagina siete. 12 de octubre de 2020. https://www.paginasiete.bo/nacional/2020/10/12/mujerescreando-pinta-viste-de-chola-la-escultura-de-isabel-la-catolica-271247.html?

fbclid=IwAR1r9TaCCGzh9kud4LEocHn3sTAiwALhyXn15zMrVAdno5tCIFM_pf8sxS0 Consultado el $10 / 06 / 2021$

Pérez Benavides, A. y Vargas Álvarez, S. (2021). «De Estatuas, conquistadores y colonialismo». El Espectador, 04/ 11/ 2020. https://www.elespectador.com/el-magazin-cultural/de-estatuasconquistadores-y-colonialismo-article/ Consultado el 10/06/2021

Sánchez Gómez, G. (2011). Proyecto para un memorial, Oscar Muñoz, Protografías. Exposición retrospectiva, Museo de Arte del Banco de la República, pp. 72-77.

\section{NOTES}

1. En referencia a la novela de ciencia ficción ¿Sueñan los androides con ovejas eléctricas? de Philip K. Dick."

\section{AUTHOR}

\section{PAOLO VIGNOLO}

Universidad Nacional de Colombia, Bogotá.

Correo electrónico: pvignolo@unal.edu.co 